\title{
Generation of functional human hepatocytes in vitro: current status and future prospects
}

\author{
Tomoko Yamaguchi ${ }^{1}, 2$, Juntaro Matsuzaki ${ }^{2,3}$, Takeshi Katsuda ${ }^{2}$, Yoshimasa Saito ${ }^{1}$, Hidetsugu Saito ${ }^{1}$ and \\ Takahiro Ochiya ${ }^{2,4^{*}}$
}

\begin{abstract}
Liver and hepatocyte transplantation are the only effective therapies for late-stage liver diseases, in which the liver loses its regenerative capacity. However, there is a shortage of donors. As a potential alternative approach, functional hepatocytes were recently generated from various cell sources. Analysis of drug metabolism in the human liver is important for drug development. Consequently, cells that metabolize drugs similar to human primary hepatocytes are required. This review discusses the current challenges and future perspectives concerning hepatocytes and hepatic progenitor cells that have been reprogrammed from various cell types, focusing on their functions in transplantation models and their ability to metabolize drugs.
\end{abstract}

Keywords: Hepatocyte, Regeneration, Progenitor cells, Drug metabolism

\section{Background}

The prognosis of patients with end-stage liver cirrhosis and fulminant hepatitis is poor unless they receive a liver transplant [1]. Unfortunately, there is a shortage of transplantable organs, and consequently, alternatives have been explored. Although the resected human liver has an enormous regenerative capacity [2], the functions of primary human hepatocytes decrease upon conventional two-dimensional culture on an extracellular matrix-coated surface. Functional human hepatocytes can be generated in vitro due to recent technological advances in the stem cell research field [3]. This approach could be an abundant source of cells for therapeutic applications. In addition, in vitro culture of human hepatocytes and/or their progenitors may help to increase understanding of liver development and regeneration following injury, to estimate the risk of drug-induced liver injury, to analyze the interactions between hepatocytes and hepatitis virus, to elucidate the mechanisms

\footnotetext{
*Correspondence: tochiya@ncc.go.jp

${ }^{2}$ Division of Molecular and Cellular Medicine, National Cancer Center Research Institute, 5-1-1 Tsukiji, Chuo-ku, Tokyo 104-0045, Japan

${ }^{4}$ Institute of Medical Science, Tokyo Medical University, 6-1-1 Shinjuku,

Shinjuku-ku, Tokyo 160-8402, Japan

Full list of author information is available at the end of the article
}

underlying liver carcinogenesis, and to assist the development of personalized therapies for patients with hepatocellular carcinoma. This review discusses the current challenges associated with therapeutically relevant approaches for regenerating hepatocytes in vitro and future perspectives for hepatocytes and hepatic progenitor cells reprogrammed from various cell types. Particular focus is paid to the functions of these cells in transplantation models and their ability to metabolize drugs.

\section{Main text \\ Animal models for hepatocyte transplantation experiments}

Evaluation of the repopulation rate and hepatic function of transplanted human primary hepatocytes has increased over the past two decades with the development of various mouse models (Table 1). There are three main mouse models: albumin (ALB) uroplasminogen activator (uPA) transgenic mice, mice with knockout of the fumarylacetoacetate hydrolase (Fah) gene, and ALB thymidine kinase transgenic-NOD-SCID-interleukin common mice gamma chain knockout (TK-NOG) mice [19].

In uPA/SCID mice, constitutive expression of uPA in hepatocytes causes liver injury and permits selective expansion of transplanted human hepatocytes. However, 


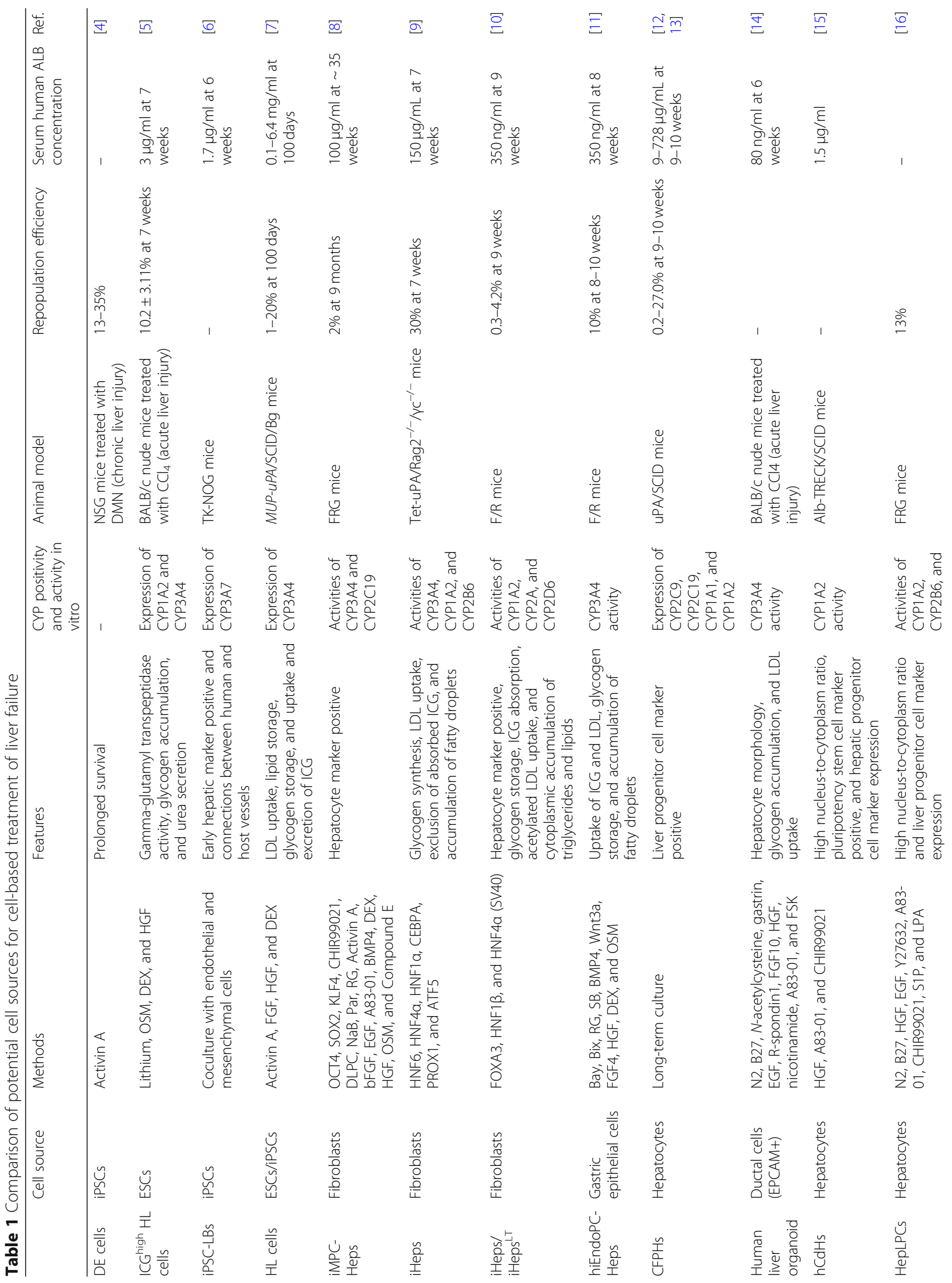




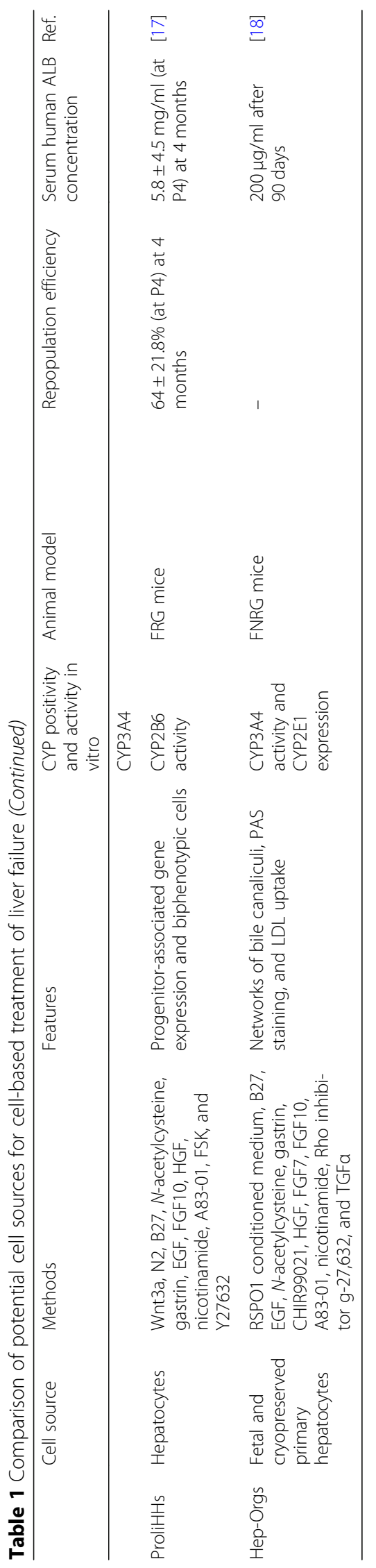


uPA/SCID mice have some disadvantages. Repopulation of human hepatocytes in the liver of these mice is decreased due to deletion of the uPA transgene by homologous recombination. In addition, hemizygotes cannot be used as hosts because homologous recombination occurs more frequently in hemizygotes than in homozygotes. To overcome these disadvantages, Tateno et al. established a novel host strain that expresses a transgene comprising the ALB promoter/enhancer and uPA cDNA and is of a SCID background (cDNA-uPA/SCID mice) [20]. Tesfaye et al. also generated a novel mouse strain that expresses the uPA gene under the control of the major urinary protein promoter and is of a SCID/beige background (MUP-uPA/SCID/Bg mice) [21]. cDNAuPA/SCID mice have the following advantages: their body is larger than that of uPA/SCID mice, it is easier to perform animal experiments, and the frequency of renal damage is decreased. MUP-uPA/SCID/Bg mice provide a long time window (up to 12 months) for hepatocyte engraftment and are efficiently infected with hepatitis B virus or hepatitis $C$ virus [22]. Tet-uPA/Rag $2^{-/-} / \gamma^{-/-}$ mice are easily bred, remain healthy prior to induction of liver injury, and have no time-window limit for liver cell transplantation.

In Fah-knockout mice, deletion of Fah, which functions in the tyrosine catabolic pathway, causes accumulation of toxic fumarylacetoacetate, resulting in liver injury. Liver disease can be controlled by administering 2-(2-nitro-4-trifluoromethylbenzoyl)-1,3-cyclohexane-

dione in these mice. Azuma et al. generated $\mathrm{Fah}^{-1-}$, $\mathrm{Rag}^{-/-} / \mathrm{Il} 2 \mathrm{rg}^{-/-}$(FRG) mice by crossing Fah-knockout mice and $\operatorname{Rag} 2^{-/-} / \mathrm{Il}_{2} \mathrm{rg}^{-1-}$ mice, which are immunodeficient and lack B, T, and NK cells [23]. The capacity for liver xeno-repopulation is reduced in $\mathrm{Fah}^{-/-} \mathrm{Rag} 2^{-/-}$(F/ R) mice due to the presence of NK cells [24]. However, F/R mice are easy to bred and tolerate hepatocyte transplantation. Fah ${ }^{-/-}$NOD Rag1 ${ }^{-/} \mathrm{Il}_{2} \mathrm{rg}^{-/-}$(FNRG) mice are more immunodeficient than FRG mice [25].

A herpes simplex virus type 1 thymidine kinase (HSVtk) transgene was expressed in the liver of highly immunodeficient NOG mice. Ganciclovir can control the hepatotoxic transgene in TK-NOG mice. In addition, TK-NOG mice mimic liver zonation and drug metabolism in the repopulated liver [26].

Azuma et al. intrasplenically transplanted human hepatocytes into FRG mice [23]. Human hepatocytes repopulated the livers of these mice with a repopulation rate of $>80 \%$. Hasegawa et al. intrasplenically transplanted human liver cells into TK-NOG mice [26]. The repopulation rate was $43 \%$ in the livers of these mice. Tateno et al. intrasplenically transplanted human hepatocytes into cDNA-uPA/SCID mice [20]. The repopulation rate was $>70 \%$ in the livers of these mice. Thus, transplanted mature human hepatocytes demonstrate a high capacity to regenerate the injured liver in mice, which indicates the feasibility of mouse models for checking the function of in vitro-derived cells.

\section{Potential alternative cell sources for hepatocyte transplantation therapy}

To overcome the shortage of donor hepatocytes, many attempts have been made to generate functional hepatocytes from multiple types of cells (Table 1). However, there is controversy regarding the usefulness of these cells for transplantation therapy. Liu et al. generated human induced pluripotent stem cell (iPSC) lines from different sources and intravenously transplanted definitive endoderm (DE) cells differentiated from these iPSC lines

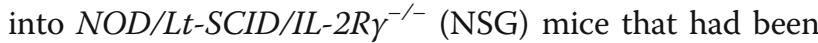
treated with dimethylnitrosamine (DMN) for 4 weeks (liver cirrhosis model) [4, 27-30]. The engraftment percentage, calculated as the percentage of human hepatic cells expressing ALB, was $13 \%$ in the livers of mice transplanted with $2 \times 10^{6} \mathrm{DE}$ cells and $35 \%$ in the livers of mice transplanted with $7 \times 10^{6} \mathrm{DE}$ cells. Woo et al. reported that embryonic stem cells (ESCs) treated with lithium and cultured in the presence of hepatocyte growth factor (HGF), oncostatin M (OSM), and dexamethasone (DEX) differentiated into cells with a hepatocyte-like (HL) morphology that expressed ALB and keratin 18, and that HL cells with high liver function were enriched using indocyanine green (ICG) $[5,31-34]$. When HL ICG ${ }^{\text {high }}$ cells were transplanted into $\mathrm{CCl}_{4}$-intoxicated $\mathrm{BALB} / \mathrm{c}$ mice (acute liver injury model), the percentage of human ALB-positive cells was lower at day $35(10.2 \pm 3.11 \%)$ than at day $3(20.2 \pm 4.45 \%)$ after transplantation. Takebe et al. revealed that hepatic endoderm cells derived from human iPSCs formed a threedimensional spherical tissue mass termed iPSC-derived liver buds (iPSC-LBs), which expressed early hepatic marker genes, upon culture with human umbilical vein endothelial cells and human mesenchymal stem cells [6]. In vitro-derived human iPSC-LBs integrated with the host vasculature within $48 \mathrm{~h}$ after transplantation. Human iPSC-LBs began producing ALB at approximately day 10 post-transplantation in TK-NOG mice and increased the concentration of ALB to $1.983 \mu \mathrm{g} / \mathrm{ml}$ by day 45. Carpentier et al. demonstrated that HL cells differentiated from iPSCs via a multistep protocol were positive for $\alpha$-1-antitrypsin (AAT) and Forkhead box a2 (FOXA2), which are endoderm cell markers, as well as hepatocyte nuclear factor 4 alpha (HNF4 $\alpha)$, which is a master regulator of hepatic differentiation. Upon transplantation of $\mathrm{HL}$ cells into the spleen of MUP-uPA/ $\mathrm{SCID} / \mathrm{Bg}$ mice, the human ALB concentration at day 10 post-engraftment was $50-3900 \mu \mathrm{g} / \mathrm{ml}[7,35,36]$.

Transdifferentiation, which refers to direct conversion of a differentiated cell type into another one without an 
intermediary pluripotent stage, could be an alternative to iPSCs for generation of functional hepatocytes. Zhu et al. transduced human fibroblasts with retroviruses expressing OCT4, SOX2, and KLF4 and then replated these cells into a medium containing established growth factors and CHIR99021 (a GSK-3 $\beta$ inhibitor) for reprogramming into endoderm cells [8]. Upon addition of A83-01 (a transforming growth factor- $\beta$ inhibitor) and Compound E (a Notch signaling inhibitor) to inhibit biliary differentiation, these cells differentiated into induced multipotent progenitor cell hepatocytes (iMPCHeps) that expressed hepatocyte markers. Following transplantation of iMPC-Heps into FRG mice, human ALB was detected in mouse serum at 2 months posttransplantation and reached a concentration of $104 \mu \mathrm{g} /$ $\mathrm{ml}$ after 6 months, with a liver repopulation efficiency of $2 \%$. $\mathrm{Du}$ et al. demonstrated that overexpression of HNF6, HNF4 $\alpha$, and HNF1 $\alpha$ induced differentiation of fibroblasts into cells that were morphologically similar to hepatocytes ( $3 \mathrm{H}$ cells). They also overexpressed CEBPA, PROX1, and ATF5 in 3H cells and observed a dramatic morphological change of fibroblasts into epithelial cells within 1 week (iHeps) [9]. iHeps were intrasplenically transplanted into Tet-uPA/Rag2 $2^{-/-} / \mathrm{\gamma c}^{-/-}$mice [37]. The concentration of human ALB in mouse serum gradually increased and peaked at $313 \mathrm{ng} / \mathrm{ml}$ at 7 weeks posttransplantation, with a repopulation efficiency of approximately $30 \%$. Huang et al. reported that overexpression of FOXA3, HNF1 $\beta$, and HNF4 $\alpha$ induced high levels of hepatic gene expression in fibroblasts at 12 days after induction (iHeps) [10]. When iHeps transfected with the SV40 large $\mathrm{T}$ antigen were transplanted into $\mathrm{F} / \mathrm{R}$ mice, staining of human Fah and AAT showed that these cells repopulated $0.3-4.2 \%$ of the liver parenchyma in surviving mice [23]. Transdifferentiation of fibroblasts was induced via gene transfer in these three reports. On the other hand, Wang et al. demonstrated that treatment with four small molecules (Bay K 8644, Bix01294, RG108, and SB431542) converted gastric epithelial cells into induced endodermal progenitor cells (hiEndoPCs) with a multilineage differentiation capacity [11]. Transplanted hiEndoPC-derived hepatic cells (hiEndoPCHeps) with hepatocyte-specific functions rescued liver failure in F/R mice. Moreover, human ALB levels were comparable to those from either hESC-Heps, with a maximum repopulation efficiency of $10 \%$.

Several recent studies proposed that hepatocytes are a source of expandable hepatic cells. In 2008, Utoh et al. identified a small population of replicative hepatocytes, termed colony-forming parenchymal hepatocytes (CFPHs), in long-term cultures of human adult hepatocytes. The frequency of these cells was $0.01-0.09 \%$ depending on donor age $[12,13]$. When CFPHs were transplanted into uPA/SCID mice, they engrafted into the liver and grew for at least 10 weeks. Moreover, the maximum repopulation rate was $27 \%$ and the maximum human ALB concentration was $728 \mu \mathrm{g} / \mathrm{ml}$. In an attempt to generate cells that proliferate more rapidly than CFPHs and that exhibit a repopulative capacity and hepatocyte functions after transplantation, we previously reported that a cocktail of three small chemicals, namely, Y27632, A83-01, and CHIR99021 (YAC), effectively converted rodent mature hepatocytes into liver progenitors, termed chemically induced liver progenitors [38]. However, Kim et al. reported that YAC-treated human hepatocytes rapidly died without proliferating [15]. To overcome this problem, they searched for additional hepatic factors that increased the efficiency of conversion. Given that HGF is important for liver organogenesis, liver regeneration, and maintenance of hepatic progenitor cells [39-41], they supplemented the reprogramming medium with this molecule and tested the effects of various combinations of small molecules together with HGF. A combination of HGF and two small molecules, namely, A83-01 and CHIR99021, was most effective. Human chemically derived hepatic progenitors (hCdHs) formed within 10-15 days of treatment with this combination. When hCdHs were transplanted into Alb-TRECK/SCID mice, they engrafted and repopulated about $20 \%$ of the diseased parenchyma within 3 weeks, and the ALB concentration reached $>1 \mu \mathrm{g} / \mathrm{ml}$. Fu et al. developed transition and expansion medium (EM), which can be used to convert human hepatocytes into hepatocyte-derived liver progenitor-like cells (HepLPCs) in vitro $[16,42]$. When HepLPC-derived hepatocytes (HepLPC-Heps) were transplanted into F/R mice, human ALB-positive cells covered $7.2-16.1 \%$ of the liver parenchyma in surviving mice. In 2015, Huch et al. reported that leucine-rich orphan G-protein-coupled receptor 5-positive cells isolated from the human liver expanded and became bile duct-derived bipotent progenitor cells upon culture in EM [14, 43]. When these cells were engrafted into BALB/c nude mice that had been administered $\mathrm{CCl}_{4}$-retrorsine to induce acute liver failure, human ALB was detected in mouse serum within 7-14 days. Using a similar method as culture in the presence of YAC and EM, Zhang et al. revealed that culture in human liver isolation medium, which contained the same supplements as EM and lacked R-spondin1, Noggin, and forskolin, was optimal to generate proliferating human hepatocytes (ProliHHs) and that Wnt3a was the key factor in this medium [17]. This indicates that Wnt3a is more important than CHIR99021 and Rspondin1 in this context. Following transplantation of ProliHHs, 11 of 14 FRG mice survived for more than 4 months, whereas all FRG mice not transplanted with hepatocytes died within 4 months. Importantly, the concentration of human ALB in mouse serum was $5.8 \mathrm{mg} /$ 
$\mathrm{ml}$ after 4 months. The repopulated ProliHHs expressed phase I and II enzymes and transporters at levels comparable with those in primary human hepatocytes after transplantation.

Hu et al. established human fetal hepatocyte organoids with a typical grape-like structure [18]. They also established organoids from cryopreserved primary human hepatocytes, which had small lumina and contained large cells with a hepatocyte morphology. Notably, ALB secretion by the latter organoids was comparable with that by primary human hepatocytes. Organoids were transplanted like hepatocyte transplantations into FNRG mice via splenic injection $[44,45]$. At 90 days after transplantation, the serum human ALB in mice transplanted with human fetal hepatocyte organoids had increased by 200fold to more than $200 \mu \mathrm{g} / \mathrm{ml}$ on average. Fu et al. revealed that three-dimensional spheroid formation enhanced hepatic differentiation in vitro [16]. Zhang et al. reported that ProliHHs matured in three-dimensional organoid culture [17]. Thus, three-dimensional culture may contribute to the maturation of hepatocytes.

\section{Potential application of in vitro-generated hepatic cells for drug development studies}

Primary human hepatocytes are the gold standard for drug development studies. Olson et al. compared drug toxicities between humans and various animals, including dogs, primates, rats, mice, and guinea pigs [46]. Their analysis indicated that the overall concordance between human and animal toxicity was $71 \%$. Many in vitro models of the liver have been used, including liver slices, hepatic cell lines, and primary hepatocytes. Liver tissue slices exhibit zone-specific cytochrome p450 (CYP) activity and phase II enzyme expression; however, these are unstable [47]. Although hepatic cell lines provide an unlimited number of cells, their expression levels of phase I and II enzymes decrease upon repeated passage [48]. Consequently, human hepatocytes that can metabolize drugs and toxicity screening platforms are required. However, the use of primary human hepatocytes is hampered by the limited number of donors and the small number of cells that are obtained. In addition, it is difficult to maintain the proliferative capacity and function of hepatocytes in vitro [49].

Stem cell-derived hepatocytes reportedly exhibit substantial CYP enzyme activity; however, their applicability for drug testing remains controversial. Liu et al. demonstrated that human iPSC-derived hepatocytes exhibited activities of major CYP enzymes, such as CYP1A2, CYP2C9, CYP2C19, and CYP2D6, similar to primary hepatocytes [4]. Woo et al. reported that ICG ${ }^{\text {high }}$ HL cells were positive for ALB, keratin 18, HNF4 $\alpha$, and CYP1A2 and that expression of enzymes related to phase I and II drug metabolism, namely, CYP3A4 and glutathione S- transferase $1 / 2$, was enhanced in these cells according to quantitative PCR [30]. Carpentier et al. demonstrated that HL cells exhibited various hepatocyte-specific functions, including uptake of low-density lipoprotein (LDL), storage of lipids based on Oil Red O staining, storage of glycogen based on periodic acid-Schiff staining, and uptake and excretion of ICG; however, HL cells were mainly negative for CYP2D6 and only a few cells were weakly positive for CYP3A4 [32]. These studies collectively suggest that stem cell-derived hepatic cells are useful for pharmaceutical studies. However, they did not demonstrate the inducibility of CYP enzyme activities, which is a major criterion for application of cultured hepatic cells in drug development studies. A few groups described CYP inducibility in terms of enzymatic activity [50-52]. However, the number of such studies is very small, and consequently, the usefulness of stem cell-derived hepatocytes for pharmaceutical studies remains controversial.

Hepatocyte-derived expandable hepatic cells could be used instead of primary human hepatocytes in pharmaceutical studies. Kim et al. reported that omeprazole treatment significantly increased CYP1A2 activity in hCdHderived hepatocytes relative to that in $\mathrm{hCdHs}$ to a similar level as that in primary human hepatocytes [15]. Fu et al. demonstrated that omeprazole treatment increased CYP1A2 expression by $80 \pm 11$-fold to $193 \pm 27$-fold, CITCO treatment increased CYP2B6 expression by $10 \pm$ 2-fold to $26 \pm 4$-fold, and rifampicin treatment increased CYP3A4 expression by $47 \pm 2$-fold to $96 \pm 5$-fold (in comparison with the DMSO-treated control) in HepLPCsHeps [16]. Furthermore, HepLPCs-Heps metabolized acetaminophen, $\mathrm{OH}$-bupropion, $\mathrm{OH}$-diclofenac, $\mathrm{OH}$ testosterone, and $\mathrm{OH}$-coumarin Glu to a similar extent as primary hepatocytes. Zhang et al. reported that CYP2B6 metabolic activity in ProliHHs increased after maturation, in accordance with increased mRNA expression of genes involved in CYP2B6 metabolism [17]. These reports strongly suggest that hepatocyte-derived expandable cells have an advantage over stem cell-derived hepatic cells in terms of CYP inducibility.

\section{Future perspectives}

In the past decade, significant progress has been made in the development of hepatocyte replacement therapy as an alternative to liver transplantation for severe liver failure. Importantly, the use of autologous cell sources would obviate the need for systemic immune suppression, which is required after liver transplantation. Previous reports tend to only describe the ideal data (publication bias), and consequently, it is difficult to compare their results. Approaches to standardize the methods for functional evaluation of these cells must be discussed. Cells must be sufficiently expandable for therapeutic applications. Repeated passage can change 


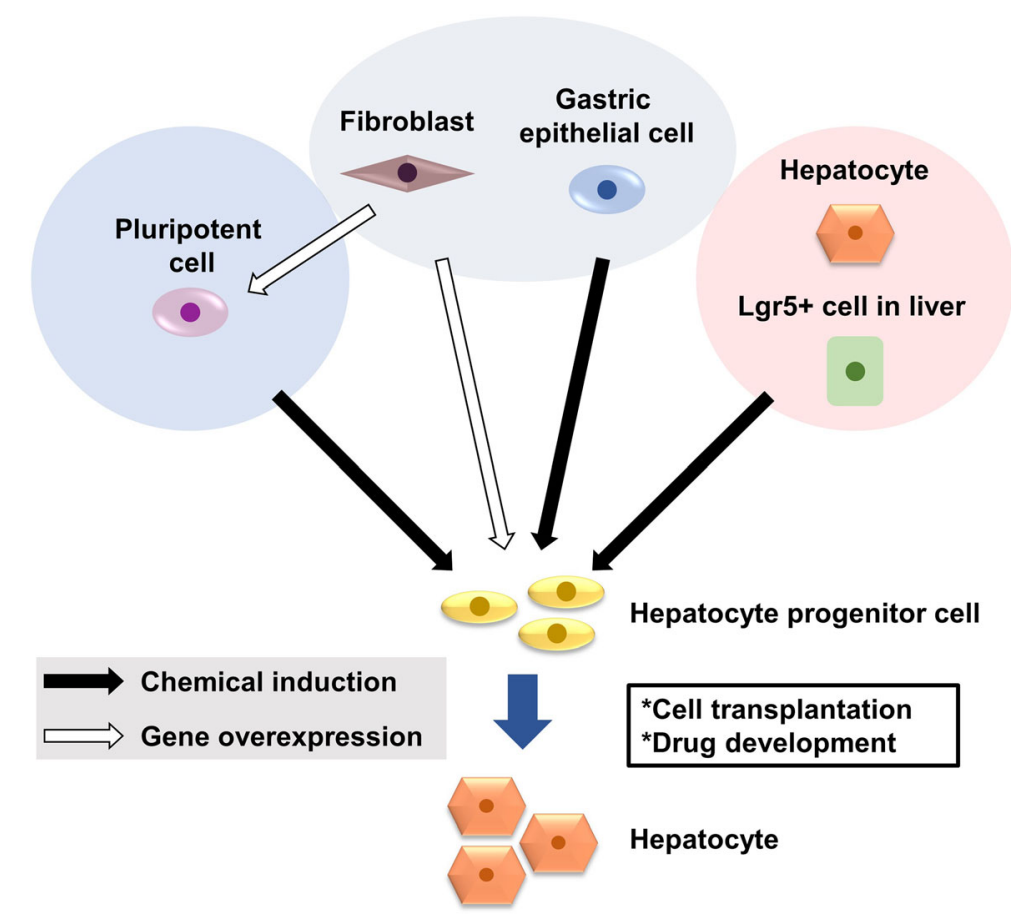

Fig. 1 Approaches to generate hepatocyte progenitors in vitro. Current approaches to generate in vitro-expandable hepatocytes include differentiation of human pluripotent stem cells, reprogramming of fibroblasts and cells of a similar developmental origin, identification of liver progenitor cells, and reprogramming of mature hepatocytes. In vitro-expandable hepatocytes are required as a therapeutic alternative to liver transplantation and for drug development

the quality of cells. Serum human ALB levels and repopulation efficiencies in several animal models of liver disease provide reliable data to evaluate cell functions. Secretion of ALB by transplanted cells is higher in recent studies than in older studies (Table 1). The safety of cell replacement therapy must also be considered. In particular, the risk of tumor formation following transplantation of cells reprogrammed via gene transfer must be thoroughly investigated. Generation of mature hepatocyte-derived progenitors via treatment with small molecules is currently the best strategy in terms of cell function and safety. Further studies are required to determine whether mature hepatocytes obtained from patients with severe liver disease such as cirrhosis can be converted into progenitors with sufficient functions.

In vitro culture of functional hepatocytes may facilitate the evaluation of drug metabolism, which would accelerate the safety assessment of new drugs. Personalized assessment of the hepatic side effects of drugs may also be possible using in vitro models generated using a person's own hepatocytes. Therefore, in vitro drug metabolism should be considered when selecting a strategy to generate hepatocytes.

The rapid development of genome editing technologies means that genetic changes can be introduced into hepatocyte progenitors in a site-specific manner, including correction of disease-causing gene mutations in patientderived hepatocytes. This approach may enable us to cure congenital/inherited metabolic diseases. On the other hand, the introduction of specific mutations into nondiseased hepatocyte progenitors could be used to generate ideal disease models. This approach could be used to investigate the mechanisms underlying liver carcinogenesis.

\section{Conclusion}

In vitro-expandable hepatocytes are required as therapeutic alternatives to liver transplantation and for drug development. Three strategies have been proposed to generate functional hepatocytes: (i) generation of hepatocytes from ESCs or iPSCs, (ii) transdifferentiation of fibroblasts and other differentiated cells into hepatocytes, and (iii) chemical induction of hepatocyte progenitors from mature hepatocytes (Fig. 1). Standardized methods to evaluate cell functions are required to compare these methods. The coming decade will reveal which strategy holds the most promise for translation into clinical applications.

\section{Abbreviations}

ALB: Albumin; CFPH: Colony-forming parenchymal hepatocyte;

CYP: Cytochrome p450; DE: Definitive endoderm; DEX: Dexamethasone; DMN: Dimethylnitrosamine; EM: Expansion medium; ESC: Embryonic stem cell; F/R: Fah ${ }^{-1-}$ Rag2 $^{-1-}$; FOXA2: Forkhead box a2; FRG: Fah ${ }^{-/} /$Rag2 $^{-1-} /$ 
$112 \mathrm{rg}^{-/-} ; \mathrm{hCdH}$ : Human chemically derived hepatic progenitor; HepLPC: Hepatocyte-derived liver progenitor-like cell; HepLPC-Hep: HepLPCderived hepatocyte; HGF: Hepatocyte growth factor; hiEndoPC: Human induced endodermal progenitor cell; hiEndoPC-Hep: hiEndoPC-derived hepatic cell; HL: Hepatocyte-like; HNF4a: Hepatocyte nuclear factor 4 alpha; ICG: Indocyanine green; iMPC-Hep: Induced multipotent cell progenitor hepatocyte; iPSC: Induced pluripotent stem cell; iPSC-LB: iPSC-derived liver

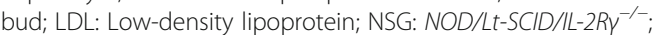

OSM: Oncostatin M; ProliHH: Proliferating human hepatocyte; YAC: Y27632, A83-01, and CHIR99021

\section{Authors' contributions}

TY and JM wrote the manuscript. TK, YS, HS, and TO revised the manuscript All authors read and approved the final manuscript.

\section{Funding}

This research was funded by a Grant-in-Aid for Scientific Research (C) (17 K09471, to JM) from the Japan Society for the Promotion of Science (JSPS).

\section{Availability of data and materials}

Not applicable

\section{Ethics approval and consent to participate}

Not applicable

\section{Consent for publication}

Not applicable

\section{Competing interests}

The authors declare that they have no competing interests.

\section{Author details}

${ }^{1}$ Division of Pharmacotherapeutics, Keio University Faculty of Pharmacy, 1-5-30 Shibakoen, Minato-ku, Tokyo 105-8512, Japan. ${ }^{2}$ Division of Molecular and Cellular Medicine, National Cancer Center Research Institute, 5-1-1 Tsukiji, Chuo-ku, Tokyo 104-0045, Japan. ²Division of Gastroenterology and Hepatology, Department of Internal Medicine, Keio University School of Medicine, 35 Shinanomachi, Shinjuku-ku, Tokyo 160-8582, Japan. ${ }^{4}$ Institute of Medical Science, Tokyo Medical University, 6-1-1 Shinjuku, Shinjuku-ku, Tokyo 160-8402, Japan

\section{Received: 10 March 2019 Accepted: 22 May 2019}

Published online: 02 July 2019

\section{References}

1. Dhawan A, Puppi J, Hughes RD, Mitry RR. Human hepatocyte transplantation: current experience and future challenges. Nat Rev Gastroenterol Hepatol. 2010;7(5):288-98.

2. Michalopoulos GK. The liver is a peculiar organ when it comes to stem cells. Am J Pathol. 2014;184(5):1263-7.

3. Tanaka M, Miyajima A. Liver regeneration and fibrosis after inflammation. Inflamm Regen. 2016;36:19.

4. Liu H, Kim Y, Sharkis S, Marchionni L, Jang YY. In vivo liver regeneration potential of human induced pluripotent stem cells from diverse origins. Sci Transl Med. 2011;3(82):82ra39.

5. Woo DH, Kim SK, Lim HJ, Heo J, Park HS, Kang GY, Kim SE, You HJ, Hoeppner DJ, Kim Y, et al. Direct and indirect contribution of human embryonic stem cell-derived hepatocyte-like cells to liver repair in mice. Gastroenterology. 2012;142(3):602-11.

6. Takebe T, Sekine K, Enomura M, Koike H, Kimura M, Ogaeri T, Zhang RR, Ueno Y, Zheng YW, Koike N, et al. Vascularized and functional human liver from an iPSC-derived organ bud transplant. Nature. 2013;499(7459):481-4.

7. Carpentier A, Tesfaye A, Chu V, Nimgaonkar I, Zhang F, Lee SB, Thorgeirsson SS, Feinstone SM, Liang TJ. Engrafted human stem cellderived hepatocytes establish an infectious HCV murine model. J Clin Invest. 2014;124(11):4953-64

8. Zhu S, Rezvani M, Harbell J, Mattis AN, Wolfe AR, Benet LZ, Willenbring $H$, Ding S. Mouse liver repopulation with hepatocytes generated from human fibroblasts. Nature. 2014;508(7494):93-7.
9. Du Y, Wang J, Jia J, Song N, Xiang C, Xu J, Hou Z, Su X, Liu B, Jiang T, et al. Human hepatocytes with drug metabolic function induced from fibroblasts by lineage reprogramming. Cell Stem Cell. 2014;14(3):394-403.

10. Huang P, Zhang L, Gao Y, He Z, Yao D, Wu Z, Cen J, Chen X, Liu C, Hu Y, et al. Direct reprogramming of human fibroblasts to functional and expandable hepatocytes. Cell Stem Cell. 2014;14(3):370-84.

11. Wang Y, Qin J, Wang S, Zhang W, Duan J, Zhang J, Wang X, Yan F, Chang M, Liu X, et al. Conversion of human gastric epithelial cells to multipotent endodermal progenitors using defined small molecules. Cell Stem Cell. 2016;19(4):449-61.

12. Utoh R, Tateno C, Yamasaki C, Hiraga N, Kataoka M, Shimada T, Chayama K, Yoshizato K. Susceptibility of chimeric mice with livers repopulated by serially subcultured human hepatocytes to hepatitis B virus. Hepatology. 2008:47(2):435-46

13. Yamasaki C, Tateno C, Aratani A, Ohnishi C, Katayama S, Kohashi T, Hino H, Marusawa H, Asahara T, Yoshizato K. Growth and differentiation of colonyforming human hepatocytes in vitro. J Hepatol. 2006:44(4):749-57.

14. Huch M, Gehart H, van Boxtel R, Hamer K, Blokzijl F, Verstegen MM, Ellis $\mathrm{E}$, van Wenum $\mathrm{M}$, Fuchs SA, de Ligt J, et al. Long-term culture of genome-stable bipotent stem cells from adult human liver. Cell. 2015; 160(1-2):299-312.

15. Kim Y, Kang K, Lee SB, Seo D, Yoon S, Kim SJ, Jang K, Jung YK, Lee KG, Factor VM, et al. Small molecule-mediated reprogramming of human hepatocytes into bipotent progenitor cells. J Hepatol. 2019;70(1):97-107.

16. Fu GB, Huang WJ, Zeng M, Zhou X, Wu HP, Liu CC, Wu H, Weng J, Zhang $H D$, Cai YC, et al. Expansion and differentiation of human hepatocytederived liver progenitor-like cells and their use for the study of hepatotropic pathogens. Cell Res. 2019;29(1):8-22.

17. Zhang K, Zhang L, Liu W, Ma X, Cen J, Sun Z, Wang C, Feng S, Zhang Z, Yue $L$, et al. In vitro expansion of primary human hepatocytes with efficient liver repopulation capacity. Cell Stem Cell. 2018;23(6):806-819 e804.

18. Hu H, Gehart H, Artegiani B, LO-I C, Dekkers F, Basak O, van Es J, Chuva de Sousa Lopes SM, Begthel H, Korving J, et al. Long-term expansion of functional mouse and human hepatocytes as 3D organoids. Cell. 2018; 175(6):1591-1606 e1519.

19. Grompe M, Strom S. Mice with human livers. Gastroenterology. 2013;145(6): 1209-14.

20. Tateno C, Kawase Y, Tobita Y, Hamamura S, Ohshita H, Yokomichi H, Sanada H, Kakuni M, Shiota A, Kojima Y, et al. Generation of novel chimeric mice with humanized livers by using hemizygous CDNA-UPA/SCID mice. PLoS One. 2015;10(11):e0142145.

21. Tesfaye A, Stift J, Maric D, Cui Q, Dienes HP, Feinstone SM. Chimeric mouse model for the infection of hepatitis B and C viruses. PLoS One. 2013;8(10): e77298.

22. Wang Z, Wu N, Tesfaye A, Feinstone S, Kumar A. HCV infection-associated hepatocellular carcinoma in humanized mice. Infect Agent Cancer. 2015;10:24.

23. Azuma H, Paulk N, Ranade A, Dorrell C, Al-Dhalimy M, Ellis E, Strom S, Kay MA, Finegold M, Grompe M. Robust expansion of human hepatocytes in Fah-/-/Rag2-/-/I2rg-/- mice. Nat Biotechnol. 2007;25(8):903-10.

24. He Z, Zhang H, Zhang X, Xie D, Chen Y, Wangensteen KJ, Ekker SC, Firpo M, Liu C, Xiang D, et al. Liver xeno-repopulation with human hepatocytes in Fah-/-Rag2-/- mice after pharmacological immunosuppression. Am J Pathol. 2010:177(3):1311-9.

25. Stevens KR, Scull MA, Ramanan V, Fortin CL, Chaturvedi RR, Knouse KA, Xiao JW, Fung C, Mirabella T, Chen AX, et al. In situ expansion of engineered human liver tissue in a mouse model of chronic liver disease. Sci Transl Med. 2017;9(399):eaah5505.

26. Hasegawa M, Kawai K, Mitsui T, Taniguchi K, Monnai M, Wakui M, Ito M, Suematsu M, Peltz G, Nakamura M, et al. The reconstituted 'humanized liver' in TK-NOG mice is mature and functional. Biochem Biophys Res Commun. 2011;405(3):405-10.

27. Locke JE, Sun Z, Warren DS, Sheets TP, Holzer H, Shamblott MJ, Montgomery RA, Cameron AM. Generation of humanized animal livers using embryoid body-derived stem cell transplant. Ann Surg. 2008;248(3): 487-93

28. Nishibe $Y$, Kaneko H, Suzuki H, Abe T, Matsuura Y, Takaku H. Baculovirusmediated interferon alleviates dimethylnitrosamine-induced liver cirrhosis symptoms in a murine model. Gene Ther. 2008;15(13):990-7.

29. Yoshida T, Ogata H, Kamio M, Joo A, Shiraishi H, Tokunaga Y, Sata M, Nagai $\mathrm{H}$, Yoshimura A. SOCS1 is a suppressor of liver fibrosis and hepatitis-induced carcinogenesis. J Exp Med. 2004;199(12):1701-7. 
30. Ogiso T, Nagaki M, Takai S, Tsukada Y, Mukai T, Kimura K, Moriwaki H. Granulocyte colony-stimulating factor impairs liver regeneration in mice through the up-regulation of interleukin-1beta. J Hepatol. 2007;47(6):816-25.

31. Lickert H, Domon C, Huls G, Wehrle C, Duluc I, Clevers H, Meyer BI, Freund JN, Kemler R. Wnt/(beta)-catenin signaling regulates the expression of the homeobox gene Cdx1 in embryonic intestine. Development. 2000;127(17): 3805-13.

32. Gadue P, Huber TL, Paddison PJ, Keller GM. Wnt and TGF-beta signaling are required for the induction of an in vitro model of primitive streak formation using embryonic stem cells. Proc Natl Acad Sci U S A. 2006; 103(45):16806-11.

33. Hay DC, Fletcher J, Payne C, Terrace JD, Gallagher RC, Snoeys J, Black JR, Wojtacha D, Samuel K, Hannoun Z, et al. Highly efficient differentiation of hESCs to functional hepatic endoderm requires ActivinA and Wnt3a signaling. Proc Natl Acad Sci U S A. 2008;105(34):12301-6.

34. Klein PS, Melton DA. A molecular mechanism for the effect of lithium on development. Proc Natl Acad Sci U S A. 1996;93(16):8455-9.

35. Tesfaye M, Silverstein KA, Nallu S, Wang L, Botanga CJ, Gomez SK, Costa LM, Harrison MJ, Samac DA, Glazebrook J, et al. Spatio-temporal expression patterns of Arabidopsis thaliana and Medicago truncatula defensin-like genes. PLoS One. 2013;8(3):e58992.

36. Weglarz TC, Degen JL, Sandgren EP. Hepatocyte transplantation into diseased mouse liver. Kinetics of parenchymal repopulation and identification of the proliferative capacity of tetraploid and octaploid hepatocytes. Am J Pathol. 2000;157(6):1963-74.

37. Song X, Guo Y, Duo S, Che J, Wu C, Ochiya T, Ding M, Deng H. A mouse model of inducible liver injury caused by tet-on regulated urokinase for studies of hepatocyte transplantation. Am J Pathol. 2009;175(5):1975-83.

38. Katsuda T, Kawamata M, Hagiwara K, Takahashi RU, Yamamoto Y, Camargo FD, Ochiya T. Conversion of terminally committed hepatocytes to culturable bipotent progenitor cells with regenerative capacity. Cell Stem Cell. 2017; 20(1):41-55.

39. Suarez-Causado A, Caballero-Diaz D, Bertran E, Roncero C, Addante A, Garcia-Alvaro M, Fernandez M, Herrera B, Porras A, Fabregat I, et al. HGF/CMet signaling promotes liver progenitor cell migration and invasion by an epithelial-mesenchymal transition-independent, phosphatidyl inositol-3 kinase-dependent pathway in an in vitro model. Biochim Biophys Acta. 2015;1853(10 Pt A):2453-63.

40. Kitade M, Factor VM, Andersen JB, Tomokuni A, Kaji K, Akita H, Holczbauer A, Seo D, Marquardt JU, Conner EA, et al. Specific fate decisions in adult hepatic progenitor cells driven by MET and EGFR signaling. Genes Dev. 2013;27(15):1706-17

41. Kwon YJ, Lee KG, Choi D. Clinical implications of advances in liver regeneration. Clin Mol Hepatol. 2015;21(1):7-13.

42. Wu H, Zhou X, Fu GB, He ZY, Wu HP, You P, Ashton C, Wang X, Wang HY, Yan HX. Reversible transition between hepatocytes and liver progenitors for in vitro hepatocyte expansion. Cell Res. 2017:27(5):709-12.

43. Huch M, Dorrell C, Boj SF, van Es JH, Li VS, van de Wetering M, Sato T, Hamer K, Sasaki N, Finegold MJ, et al. In vitro expansion of single Lgr5+ liver stem cells induced by Wnt-driven regeneration. Nature. 2013;494(7436): 247-50.

44. Billerbeck E, Mommersteeg MC, Shlomai A, Xiao JW, Andrus L, Bhatta A, Vercauteren K, Michailidis E, Dorner M, Krishnan A, et al. Humanized mice efficiently engrafted with fetal hepatoblasts and syngeneic immune cells develop human monocytes and NK cells. J Hepatol. 2016;65(2):334-43.

45. Grompe M. Fah knockout animals as models for therapeutic liver repopulation. Adv Exp Med Biol. 2017:959:215-30.

46. Olson H, Betton G, Robinson D, Thomas K, Monro A, Kolaja G, Lilly P, Sanders J, Sipes G, Bracken W, et al. Concordance of the toxicity of pharmaceuticals in humans and in animals. Regul Toxicol Pharmacol. 2000; 32(1):56-67

47. Soldatow $\mathrm{VY}$, Lecluyse EL, Griffith LG, Rusyn I. In vitro models for liver toxicity testing. Toxicol Res (Camb). 2013;2(1):23-39.

48. Guguen-Guillouzo C, Guillouzo A. General review on in vitro hepatocyte models and their applications. Methods Mol Biol. 2010;640:1-40

49. Bale SS, Moore L, Yarmush $M$, Jindal R. Emerging in vitro liver technologies for drug metabolism and inter-organ interactions. Tissue Eng Part B Rev. 2016;22(5):383-94

50. Inamura M, Kawabata K, Takayama K, Tashiro K, Sakurai F, Katayama K, Toyoda M, Akutsu H, Miyagawa Y, Okita H, et al. Efficient generation of hepatoblasts from human ES cells and iPS cells by transient overexpression of homeobox gene HEX. Mol Ther. 2011;19(2):400-7.

51. Pettinato G, Ramanathan R, Fisher RA, Mangino MJ, Zhang N, Wen X. Scalable differentiation of human iPSCs in a multicellular spheroid-based 3D culture into hepatocyte-like cells through direct Wnt/beta-catenin pathway inhibition. Sci Rep. 2016:6:32888.

52. Takayama K, Inamura M, Kawabata K, Katayama K, Higuchi M, Tashiro K, Nonaka A, Sakurai F, Hayakawa T, Furue MK, et al. Efficient generation of functional hepatocytes from human embryonic stem cells and induced pluripotent stem cells by HNF4alpha transduction. Mol Ther. 2012;20(1):12737.

\section{Publisher's Note}

Springer Nature remains neutral with regard to jurisdictional claims in published maps and institutional affiliations.
Ready to submit your research? Choose BMC and benefit from:

- fast, convenient online submission

- thorough peer review by experienced researchers in your field

- rapid publication on acceptance

- support for research data, including large and complex data types

- gold Open Access which fosters wider collaboration and increased citations

- maximum visibility for your research: over $100 \mathrm{M}$ website views per year

At BMC, research is always in progress.

Learn more biomedcentral.com/submissions 